Revista

ACor

das Letras

\title{
Regimes de interação em práticas de inclusão de deficientes visuais
}

\author{
Interaction regimes in the inclusion practices of visually impaired people
}

\author{
Elza Rodrigues Barbosa Peixoto \\ Universidade Federal do Tocantins \\ Palmas, Tocantins, Brasil \\ Luiza Helena Oliveira da Silva \\ Universidade Federal do Tocantins \\ Palmas, Tocantins, Brasil
}

Resumo: Neste estudo, nos propomos analisar o trabalho pedagógico de perspectiva inclusiva, fundamentada nos estudos da semiótica discursiva greimasiana, centrada mais especificamente na sociossemiótica de Eric Landowski. Mobilizamos os regimes de interação e sentido, tendo como corpus de análise o relatório de adaptação de alunos com necessidades especiais, produzido pelo setor de psicologia da escola pesquisada, tendo com base os relatos de impressões, preocupações e nas considerações gerais apontadas por cada parte envolvida no processo: professores, coordenação e aluna deficiente visual total e sua mãe. Esta análise levou-nos à observação da maneira como se efetivam os processos de significação resultantes da interação entre os sujeitos para compreender os mecanismos de produção de sentido nessas práticas e em que medida os ajustamentos sensíveis se vinculam ao processo de inclusão.

Palavras-chave: Inclusão. Sociossemiótica. Regimes de Interação e Sentido.

\begin{abstract}
We analyze the pedagogical work of inclusive perspective in this paper. We refer to the Greimasian discursive semiotics studies, and we focus on the Eric Landowski's social semiotics. We mobilize the interaction and sense regimes by observing the students with special needs adaptation report as an analysis corpus. The department of psychology of the researched school produced it. In addition, it relies on reports of impressions, concerns and general considerations identified by each one involved in the process: teachers, coordination and full visually impaired student and his/her mother. This analysis led us to observe the way the processes of signification become effective. They result from the interaction among the subjects to understand the mechanisms that produce sense in these practices. Insofar as the sensitive adjustments connects to the process of inclusion.
\end{abstract}

Keywords: Inclusion. Social semiotics. Interaction and Sense Regimes.

*Estudante de doutorado da Universidade Federal do Tocantins. E-mail: elza.peixoto21@gmail.com.

**Doutora em Letras, docente da Universidade Federal do Tocantins. E-mail: luiza.to@mail.uft.edu.br. 


\section{INTRODUÇÃO}

A escola não pode tudo, mas pode mais. Pode acolher as diferenças. É possível fazer uma pedagogia que não tenha medo da estranheza, do diferente, do outro. A aprendizagem é destoante e heterogênea. (ABRAMOWICZ, 1997).

Refletir sobre o fazer pedagógico é refletir sobre o uso da linguagem, pois esse fazer se constitui por meio dela, a partir da relação do sujeito com o outro à sua volta e com o saber que mobiliza. É nessa relação que se constroem e circulam os saberes, é nessa relação de interação que se constroem os sentidos das práticas.

Interessa-nos, de modo especial, a relação no âmbito do ensino, uma relação de interação entre o sujeito/professor, o sujeito/aluno e o objeto/conhecimento num espaço onde se estabelecem essas práticas: a sala de aula. Só isso já seria campo vasto de investigações pertinentes, mas tomaremos um rumo bastante pontual nessa análise: investigar, sob a ótica da inclusão, os regimes de interação constituídos nas práticas pedagógicas em uma turma regular que recebe uma aluna com deficiência visual total.

As propostas de inclusão para alunos com deficiências ingressarem na rede de ensino regular têm provocado uma série de discussões e mobilização da escola na compreensão de seu papel de responsável por garantir a todos o direito à educação. Todo processo de ensino implica necessariamente o envolvimento de seus responsáveis com ações que objetivem alcançar, com êxito, tal proposição.

Embora a Política Nacional de Educação Especial na Perspectiva da Educação Inclusiva, inserido no Plano de Desenvolvimento da Educação - PDE, instituído pelo Decreto $\mathrm{n}^{\circ}$ 6.094/2007, represente "um novo marco teórico e político da educação brasileira", as escolas enfrentam muitas dificuldades em trabalhar com essas questões. São dificuldades que vão desde a acessibilidade e integração desse aluno até mesmo à aceitação e adaptação do trabalho pedagógico concernente a essa realidade. O problema em questão parece advir do discurso de democratização do ensino como possibilidade de garantir e manter todas as crianças na escola. O desejo de democratização e o ideal de uma escola de qualidade a todas as crianças acabam não sendo suficientes para efetivar posturas coerentes de toda a comunidade educacional para receber alunos com necessidades especiais. Estamos, portanto, diante de um querer e também um dever, que não se traduzem necessariamente como sinônimos de poder e saber fazer.

Tratar desse tema se reveste de especial importância pelo fato de que a inclusão se constitui como algo relativamente recente na realidade educacional brasileira, embora a legislação e a luta por esse processo venham de mais longa data, quando os confrontos entre educadores e especialistas eram ainda maiores (FERREIRA, P. \& GONÇALVES, A. G, 2007; AMARILIAN, 2009).

Vale ressaltar ainda que não se trata de inserir na escola regular parcelas de alunos da educação especial, mas de oferecer oportunidades para que todas as crianças tenham 
possibilidades reais de construção do seu conhecimento, interagir com outras, desenvolver suas potencialidades, preparar-se para a vida, com independência e liberdade para viver e conviver em sociedade.

Os desafios são vários e constantes, as escolas estão recebendo alunos especiais, mas nem todas têm preocupação com o trabalho pedagógico em sala de aula. Mesmo sendo um assunto muito discutido atualmente, as dúvidas, medos e incertezas de como trabalhar com crianças com necessidades especiais ainda são muito comuns. Assim como é muito comum ouvir dos professores e auxiliares de sala que se sentem despreparados para trabalharem a inclusão.

Diante desses desafios, uma pergunta motiva essa investigação: como se dão os sentidos advindos das interações no contexto da inclusão de uma aluna completamente cega em uma sala de aula regular? Quais são as opções que os sujeitos (docentes) assumem em seus discursos e práticas com a finalidade de pôr o conhecimento em circulação?

Assim, põe-se em questão, neste estudo, o trabalho pedagógico de perspectiva inclusiva, fundamentada nos estudos da semiótica discursiva greimasiana, centrada mais especificamente na sociossemiótica de Eric Landowski, mobilizando para a análise os regimes de interação e sentido. Com o objetivo de investigar os processos de significação resultantes da interação entre os sujeitos professor e alunos e entre os sujeitos e o objeto de valor: o conhecimento, buscamos compreender os mecanismos de produção de sentido nessas práticas e em que medida os ajustamentos sensíveis se vinculam ao processo de inclusão.

Dadas as incertezas que pairam em torno de tais questões, compreende-se como ponto de partida uma reflexão a respeito dos discursos de professores sobre um não saber fazer, quando se deparam em sala de aula com aluno de necessidades especiais, podendo determinar muitas vezes um não querer fazer ou não poder fazer.

Assim, levam-se em consideração, neste trabalho, as palavras de Landowski (2016) sobre o que ele define como "a diversidade de práticas educativas", tendo em vista as "causas dos problemas" que advêm dessas práticas as quais "deveriam ser analisáveis a partir da distinção dos regimes de interação, pautados pelo princípio da regularidade vs. de aleatoriedade, e de intencionalidade vs. de sensibilidade" (LANDOWSKI, 2016, p.10).

Para compreender os regimes de sentido e interação estabelecidos nas práticas educativas em situação de inclusão, tomamos como corpus de análise o relatório de adaptação de alunos com necessidades especiais, produzido pelo setor de psicologia da escola pesquisada, uma escola da rede particular de ensino da cidade, a qual será denominada doravante escola CSC. O documento, assinado pela psicóloga da escola, coordenação de segmento e direção pedagógica, traz, além das descrições das ações dos sujeitos envolvidos (professores e aluna cega $^{1}$ ), os relatos de suas impressões, preocupações e as considerações gerais apontadas por cada parte.

\footnotetext{
1 A variação de termos que empregamos ao longo do artigo se justifica na medida em que algumas particularidades se configuram: trata-se de "deficiência visual" ou "deficiente visual" quando não se tem o tipo/nível de deficiência visual da pessoa ou quando se tratam de pessoas com diferentes tipos de deficiência visual. No caso em tela, referimo-nos à aluna Lara como cega, pois cegueira é o termo utilizado para deficiência visual total.
} 


\section{A INCLUSÃO ESCOLAR: CAMINHOS E DESAFIOS}

A legislação brasileira avançou muito, nos últimos anos, no que se refere ao embasamento da garantia dos direitos das pessoas com deficiência; no entanto, não é possível afirmar que tais direitos sejam devidamente legitimados na prática, até porque não é possível conceber como escola inclusiva apenas aquela que recebe matrícula de alunos com deficiência, mas sim as que oferecem condições adequadas ao trabalho pedagógico, preocupadas em realizar esse trabalho com qualidade.

Preceito presente na Declaração de Salamanca (1994), um dos marcos da Inclusão Escolar, ressalta que "todas as escolas devem acolher a todas as crianças", independentemente de suas condições pessoais, culturais ou sociais; incluindo crianças deficientes e superdotadas/altas habilidades, as crianças de rua, minorias étnicas, linguísticas ou culturais, de zonas desfavorecidas ou marginalizadas.

Já a Lei de Diretrizes e Base da Educação (1996) reforça que a Educação Especial deve ocorrer preferencialmente em escolas de ensino regular. Com a Política Nacional de Educação Especial na Perspectiva da Educação Inclusiva (2008), essa proposição ganha força, e os alunos com Necessidades Educacionais Especiais- NEE passam a não serem mais só de responsabilidade das escolas especiais, mas também das classes comuns, trazendo com isso um importante desafio para os sistemas escolares.

Longe de ser um ideal alcançado, a inclusão, apesar da força lei, continua sendo um desafio para as escolas, até mesmo para aquelas que se declaram preparadas para tal. $\mathrm{Na}$ prática, tanto a escola quanto o mercado de trabalho e a sociedade em geral muitas vezes não são sensíveis a essa realidade e a questão do preconceito também é um fator, infelizmente, presente nessa abordagem. Muitas vezes, o aluno com uma deficiência pontual, no caso, a visão, passa a ser considerado igualmente deficiente intelectual, julgando e determinando a limitação de sua aprendizagem. Pode, num exemplo generalizado, esse educando manter-se limitado em sala de aula a cumprir atividades diferenciadas e não adaptadas para sua necessidade especial, proporcionando, assim, a exclusão - ou segregação (LANDOWSKI, 2005).

Fazemos parte de uma sociedade excludente, mas a escola pode constituir-se como espaço privilegiado para novas práticas sociais, considerando a possibilidade de professores e alunos construírem conhecimentos e experiências, em que todos, com suas peculiaridades e diferenças, interajam em/entre grupos, superando e quebrando barreiras historicamente constituídas.

De acordo com Ferreira \& Gonçalves (2007), o que atualmente se denomina de Educação Especial faz parte do processo de inclusão de pessoas com necessidades educacionais especiais em escolas regulares, organizados com recursos e serviços educacionais especiais com vistas a dar apoio, suplementar e, quando necessário, substituir os serviços educacionais comuns, conforme bem determina a LDB, possibilitando, assim, um ensino inclusivo dos educandos com NEE. 
Temos ciência de que o processo de inclusão na educação não é de agora. Segundo as referidas autoras, a educação especial brasileira iniciou-se ainda com Dom Pedro II, fundando, em 1854, o Imperial Instituto dos Meninos Cegos, que se tornou mais tarde Instituto Benjamin Constant. Anos depois, o imperador fundava o Instituto dos SurdosMudos, passando a ser denominado depois de Instituto Nacional de Educação de Surdos (INES).

$\mathrm{Na}$ década de 60, é criada a APAE com o objetivo de possibilitar habilitação profissional a adolescentes com deficiência mental, fortalecendo-se, em 1971, com a abertura do Centro de Habilitação de Excepcionais. No final da década de 70 e nos anos 80 , os alunos com deficiência são integrados em classes regulares, movimento que vai num crescente intensificando-se devido ao reconhecimento de que a classe regular seria o melhor ambiente pedagógico para esses alunos com NEE se desenvolverem. Até que, em 1994, surge o conceito de educação inclusiva, graças à Declaração de Salamanca. Já em 1996, é sancionada a LDB, que determina a Educação Especial como modalidade de ensino em escolas regulares, consagrando a conquista (FERREIRA \& GONÇALVES, 2007).

De lá para cá, no entanto, passou-se um bom período no qual se defendia que as demandas de pessoas com necessidades educacionais especiais só poderiam ser atendidas em instituições especializadas. Condição que contribuía para a cristalização de preconceitos em relação ao desenvolvimento e a aprendizagem dessas pessoas. De modo equivalente, podemos relacionar as restrições de acesso e de interação social dos mesmos na comunidade.

Mas sob quais perspectivas as escolas ditas inclusivas desenvolvem seu trabalho? Uma palavra bastante usada e preocupante nesse contexto é "adaptação". A escola não pode ter como objetivo de inclusão a adaptação do aluno. Querer que o aluno venha a se adaptar, moldar-se à instituição só reforça que a escola não se modifica ou se transforma para atender às necessidades educacionais dos alunos. Essa postura contraria os princípios propostos na Declaração de Salamanca (1994) "[...] desenvolver uma pedagogia centralizada na criança, capaz de educar com sucesso todos os meninos e meninas, inclusive os que sofrem de deficiências graves".

Nessa linha já seguiam as observações e pesquisa de Masini (1991) sobre a formação de professores,

No mundo dos videntes, como não poderia deixar de ser, a fala que se impõe é a daqueles.
Seria absurdo negar este fato. Antes ele deve ser considerado para que se possam identificar
os conceitos, valores, definições do senso comum ditados pelo sentido da visão, pois este
quando utilizado como referencial na educação do DV, impede-o de compreender, levando-
o a uma aprendizagem mecânica. (MASINI, 1991, p.31)

Esbarra-se, nesse ponto, a grande dificuldade: entrar em contato com o DV, buscar saber sobre sua percepção para encontrar o caminho de orientação e ensino. As conclusões da referida autora registram que as transformações na aprendizagem dos alunos ocorrem em situações educacionais em que as experiências deles são consideradas. "Penetrar no mundo do DV é tão difícil quanto fazê-lo perceber o mundo como o vidente faz". Uma pergunta elementar poderia definir toda a relação de professores e alunos com 
deficiência visual: Como esse aluno percebe a sala sem a visão? O que eu (professor) conheço com o olhar poderá ser dito a ele? Reflexões como essas podem ser o início de um caminho de adequação e busca do professor com o aluno dos recursos necessários para o desenvolvimento do conhecimento e suas possibilidades (MASINI, 1991, p.37-38).

\section{UM OLHAR SENSÍVEL SOBRE AS PRÁTICAS DE INCLUSÃO E AS INTERAÇÕES NA SALA DE AULA}

Em conformidade com a abordagem de uma semiótica dedicada aos contextos didáticos ${ }^{2}$, verificamos que, pelo universo complexo do espaço escolar, surge uma combinação de modalidades nas quais se pressupõem relações tanto de junção como de união (LANDOWSKI, 2014; 2016) na dinâmica da circulação/produção do saber.

Assim, por meio das leituras depreendidas pela análise dos relatos que compõem o relatório de inclusão da escola, procuramos construir um mapeamento dos regimes de sentido que permeiam as relações de interação entre professores, aluna cega e os colegas, partimos de um olhar sob a perspectiva da inclusão para os aspectos situados entre o dever fazer do professor, postulados pela normativas legais e institucionais, e do saber fazer com suas diferentes instâncias e como esses percursos podem ser observados nas falas dos sujeitos envolvidos em processos de interação.

Nossa reflexão inicia-se pautada pela análise das práticas de inclusão baseadas nos princípios semióticos da regularidade, "princípio pressuposto por toda forma programática de interação", da intencionalidade, "base necessária para toda manipulação estratégica", da sensibilidade, "condição de toda interação sob a forma de ajuntamento" e da aleatoriedade, fator que constitui o regime de sentido e de interação do acidente, todos definidos por Landowski (2014a, p. 72) como os fundamentos dos regimes de interação e sentido nos quais nos pautamos para analisar a construção de sentido observada na interação de uma sala de aula com 28 alunos do nono ano, em uma escola particular de ensino regular, escola CSC, que teve como quebra de sua rotina a inclusão de uma aluna completamente cega.

Embora sejam tratados os regimes de interação e sentido de modo mais detalhado ao longo da análise, cumpre observar que essas são contribuições teóricas inseridas na sociossemiótica e que tem em Landowski seu grande representante. Nesse contexto, que atende significativamente às diversas manifestações do sentido, temos os quatro regimes de interação e sentido, nos quais se assentam os princípios citados anteriormente.

O regime da programação é regido pelo princípio da regularidade, ou seja, nesse regime há uma fixação de papéis que garante uma grande previsibilidade do que acontecerá (Landowski, 2014b, p.14), sendo esse o fator capaz de conferir certo domínio sob os fatos. Uma vez que "cada um desempenha seu papel, segue seu programa ou executa seu plano de atividade" (LANDOWSKI, 2014a, p.28), haverá uma ausência de riscos, conferindo, pela rigidez, um alto grau de segurança, porém um esvaziamento do sentido.

2Subsídios teóricos da semiótica didática é apresentada por Silva (2016) em breve histórico desde Greimas (1979), com seu texto Pour une sémiotiquedidactique, Hammad (2016) e Paolo Fabri (2016) chegando a Landowski (2016) com Régimes de sens et formes d'éducation, do qual nos servimos para nortear nossa análise. 
No regime da manipulação, cuja base está no princípio da intencionalidade, há o predomínio da persuasão, a lógica do "fazer-fazer", criando uma espécie de contrato no qual o sujeito é motivado à ação em função de uma série de estratégias e procedimentos persuasivos. A manipulação pressupõe "um sujeito de vontades" capaz de avaliar os valores em jogo e aderir ou não ao contrato proposto. (LANDOWSKI, 2014a, p.47).

O regime do ajustamento, por sua vez, corresponde às bases do "fazer sentir", a um regime "entre iguais", no qual as partes se coordenam "em função do que cada um dos participantes encontra, e, mais precisamente, sente na maneira de agir do outro". (LANDOWSKI, 2014a, p.48). Essa interação pressupõe sujeito coparticipante e não com um comportamento estritamente programado, logo a colaboração e a reciprocidade são ações características desse regime.

Pautado na aleatoriedade está o regime do acidente, o qual Landowski afirma que está fundamentado no risco, no sem-sentido, na imprevisibilidade do acaso. (LANDOWSKI, 2014a, p.73).

Mesmo sendo tratados individualmente, não se analisam os regimes isoladamente, mas em conjunto, formando o que se considera um sistema, principalmente quando se observa o conjunto dessas relações numa sala de aula, pois, como afirma o autor, "Lá se cruzam práticas que podem corresponder, simultaneamente ou alternadamente, a qualquer regime interacional" (LANDOWSKI, 2016, p.11). É esse o quadro teórico que orienta a leitura semiótica dos relatos de interação presentes no relatório do processo de inclusão de uma aluna completamente cega numa sala de aula regular da escola CSC.

A escola em questão, conforme afirma a psicóloga da instituição no relatório, “já possui certa experiência e organização para o trabalho com alunos com NEE", inclusive no trabalho com outras alunas com deficiência visual, porém com processos de integração bem diferentes, visto que as referidas alunas estudam na escola desde as séries iniciais, ali cresceram, dominando os espaços, são conhecidas por todos na escola e sempre são auxiliadas individualmente em sala por um profissional.

Algo novo acontece no ingresso da aluna Lara ${ }^{3}$, que chega à escola já em uma série avançada, $9^{\circ}$ ano, com o diferencial de ser independente de auxiliares e completamente alfabetizada em Braille. Essa situação provoca em todos uma condição de quebra de um saber fazer, de uma rotina, pelo menos à primeira vista. Ao contrário do que a maioria dos pais solicita da escola, a mãe de Lara fez questão de que ela permanecesse sem professor auxiliar ${ }^{4}$, pois se orgulhava da autonomia que foi desenvolvida ao longo dos anos na escola estadual na qual estudava em regime regular e frequentava a sala de recursos no contraturno, vínculo este que ainda permanece para seu aperfeiçoamento. Como poderemos ver mais adiante na análise, esse fato se caracterizou como um acontecimento na rotina dos professores dessa turma. Tomamos o termo a partir de Zilberberg (2011 p.142), que afirma

O acontecimento não pode ser apreendido senão como algo afetante, perturbador, que suspende momentaneamente o curso do tempo", produzindo um efeito capaz de mexer com

\footnotetext{
${ }^{3}$ A fim de preservar a identidade da aluna atribuímos um nome fictício.

${ }^{4}$ Refere-se ao professor de apoio conforme assegura a Lei 13.146/2015 do Estatuto da inclusão.
} 
as certezas do sujeito, que trocam "a contragosto" o "universo da medida pelo da desmedida" (ZILBERBEG, 2011, p.163).

Decorre daí a necessidade e pertinência deste estudo, uma oportunidade de analisar o sentido, percebido a partir dessa relação: professores, aluna cega e alunos videntes no cotidiano da sala de aula.

Assim, sem maiores pretensões diante da semiótica tensiva (Zilberberg, 2011), a relação que ora estabelecemos com o acontecimento tem como objetivo estabelecer os sentidos dos sujeitos afetados pelo inesperado, no caso em questão, a presença da aluna Lara, uma aluna deficiente visual que dispensa professor auxiliar (profissional mediador da relação corpo a corpo entre sujeitos professor e aluna cega, na busca pelo objeto-valor: o conhecimento) na turma de $9^{\circ}$ ano regular.

Comecemos, então, por refletir sobre o "impacto" desse "acontecimento" percebido no discurso dos professores, que doravante serão identificados por P1, P2 etc., e Lara.

\begin{tabular}{|l|l|}
\hline P1 & $\begin{array}{l}\text { Confesso que estou ainda apreensiva com o desempenho dela e com o nosso, } \\
\text { pois não tivemos nenhuma preparação de como proceder nestes casos, é bem } \\
\text { diferente da M. E., por exemplo, que foi alfabetizada primeiro a tinta e agora } \\
\text { em Braille. Mas vamos ver. Mas acho que nos sairemos bem. (grifos nossos) }\end{array}$ \\
\hline P2 & $\begin{array}{l}\text { Fiquei noites sem dormir pensando em como seria, bate um medo de não conseguir } \\
\text { explicar de modo com que ela entenda meus conteúdos. [...] Gostaria de estar } \\
\text { preparada para este momento anteriormente. Até solicitei para a (...), algum curso } \\
\text { preparatório. A gente precisa saber como fazer. (grifos nossos) }\end{array}$ \\
\hline P3 & $\begin{array}{l}\text { Como já tive outros alunos iguais a ela no estado }{ }^{5} \text { para mim está tranquilo. (grifos } \\
\text { nossos) }\end{array}$ \\
\hline P4 & $\begin{array}{l}\text { Minha maior preocupação era com os colegas, com a socialização dela, mas } \\
\text { é uma turma muito boa. Ainda bem que já aprendi fazer os materiais táteis } \\
\text { para a aluna de baixa visão do } 7^{\circ}, \text { mas na geopolítica estou preocupada como } \\
\text { será. (grifos nossos) }\end{array}$ \\
\hline P5 & $\begin{array}{l}\text { Ninguém tinha me avisado que a aluna cega era do 9 } \\
\text { quando tomei literalmente um susto } \\
\text { máquina. Fiquei nervoso. [...] Não entendi porque ela não tem auxiliar, seria } \\
\text { bem melhor se tivesse. (grifos nossos) }\end{array}$ \\
\hline P6 & $\begin{array}{l}\text { No meu primeiro contato com ela, achei que en a assustei um pouco, senti no jeito dela } \\
\text { que, pelas reações dela quando conduzi já na primeira atividade física com } \\
\text { a participação dela que ela estava bem desconfiada com meu “jeitão" e } \\
\text { desconfortável com a proposta de uma atividade coletiva, interativa com ela } \\
\text { participando.[... Na segunda semana ela já veio falar comigo que foi a }\end{array}$ \\
\hline
\end{tabular}

5 Referência do professor à escola estadual onde também atua. 
primeira vez que participava do começo ao fim de uma aula de Educação Física. (grifos nossos)

Quadro 1- A primeira impressão dos professores

Fica bastante claro que os professores que já tinham anteriormente contato com a mesma realidade (P3 e P4) se sentem mais à vontade no trabalho com a turma e encararam o fato com maior tranquilidade, enquanto que, para quem está sendo a primeira experiência, o sentimento despertado está mais ligado à angústia de um dever fazer, querer fazer, mas não saber fazer.

A ansiedade, a preocupação, a angústia gerada nesse acontecimento é geral, muito embora as reações diferissem bastante. Ao considerar o sentimento de angústia por não estarem preparados para essa nova realidade, percebe-se que isso acaba sendo considerado a razão do fracasso na missão de saber fazer dos professores. Os relatos nos apontam para o nível de reflexão a respeito dos "riscos contingentes", na medida em que os docentes não puderam "prever o inesperado" (LANDOWSKI, 2014), ainda que em função da nova legislação a situação esteja prevista.

Do outro lado, vemos que sentimentos semelhantes acometerem a aluna que, segundo o relato do professor de Educação Física (P6), em seu primeiro contato com uma situação de interação com tratamento de igualdade, de inclusão, numa disciplina antes só de videntes.

É possível perceber que os sentimentos advindos do novo, da mudança, da nova realidade, assim como as reações de cada sujeito em resposta a esses sentimentos, marcaram desde o início as relações de professores e Lara que foram determinantes no processo de inclusão. O maior ou menor envolvimento acontecido na relação entre professores e aluna Lara foram sendo construídos de acordo com a evolução das interações, regidas pela proximidade, pelo contato ou pelo afastamento, distanciamento.

\subsection{A INCLUSÃO SOB O PRINCÍPIO DA REGULARIDADE}

Para compreender a relação entre professor e alunos, de modo geral não se pode descartar a natureza que envolve seu fazer, certos princípios de regularidades que colocarão essa prática muitas vezes sob o regime da programação: o estabelecimento predefinido em planejamentos programáticos semanais, roteiros de estudos e atividades, cronogramas e avaliações, elementos que estão propostos na rotina pedagógica como caminho certo para o objetivo: a aprendizagem. Conforme Landowski (2014), essa extrema regularidade assumida no contexto didático resulta numa diminuição dos riscos, pois incide numa maior previsibilidade que garantiria ao final que os objetivos de aprendizagem fossem alcançados; por outro lado, aumenta o risco do "esvaziamento do sentido" proporcionado pelo automatismo das práticas e interações. Além disso, conforme Landowski (2016), entra em questão a própria concepção de aprendizagem implicada. Se se preconiza um ensino pela repetição do saber já assentado, temos a programação; se se trata de um saber útil, de uma instrumentalização do sujeito pressupondo uma concepção pragmática de ensino-aprendizagem, estamos diante da manipulação; se o 
que se propõe é um saber a ser construído na relação entre os sujeitos, então a concepção de ensino-aprendizagem se assenta sob o regime do ajustamento.

A entrada de uma aluna cega na escola foi então sentida como uma ruptura na previsibilidade do planejamento docente, implicando a sua própria identidade: o professor sai de um estado de saber fazer para um de não saber fazer. Recuperamos, aqui, o segmento da fala de P5, na qual se evidencia o desconforto e a solução pretendida - um professor auxiliar:

\begin{abstract}
Ninguém tinha me avisado que a aluna cega era do $9^{\circ}$, tomei literalmente um susto quando comecei a falar sobre os objetivos do ano e ela começou a usar a máquina, demorei alguns instantes para entender aquela situação. Fiquei nervoso. Estou tendo duas dificuldades naquela sala, a primeira de lidar com a situação da aluna Lara e a segunda de cumprir meu planejamento. É a sala que eu estou mais atrasado no conteúdo, minha prova foi a primeira do cronograma do $9^{\circ}$,_tenho que repetir explicações o tempo todo, para ganhar tempo quase sempre anoto no quadro e peço às colegas dela para ir ditando para ela. Não entendi porque ela não tem auxiliar, seria bem melhor se tivesse. Sem contar que a máquina na sala faz muito barulho e os demais vão acabar reclamando do incômodo. Acho que a coordenação precisa rever essa situação. Que bom que estão nos ouvindo. (grifos nossos)
\end{abstract}

Temos uma forte indicação desse professor como exemplo de programador, sua rotina não pode ser atrapalhada, ou seja, a partir do momento da entrada de Lara em sua sala, ele reclama da situação e tenta manter-se no programa. P5 assume que toda sua dificuldade advém daí: não consegue cumprir o programa, seu roteiro de aula e seu cronograma de prova ficam comprometidos. A solução encontrada por ele foi delegar a outrem, no caso às colegas da aluna, a cumprirem um papel que deveria ser dele. É possível perceber um distanciamento físico nessa relação, como uma tentativa de se preservar numa posição clássica de professor dotado da competência do saber fazer e do fazer saber, no papel temático do mestre em contraponto aos alunos reduzidos ao papel de aprendizes. Há, ainda, a tentativa de influenciar com sua percepção uma tomada de ação de forma a deixá-lo mais confortável em seu papel: "Acho que a coordenação precisa rever essa situação. Que bom que estão nos ouvindo”. Em sua fala em momento algum considerou o lado da aluna no processo de aprendizagem, apenas seu lado, a "ensinagem".

\title{
3.2 A INCLUSÃO SOB O PRINCÍPIO DA INTENCIONALIDADE
}

Se o regime de programação é regido pela regularidade, no regime de manipulação, a intencionalidade é o pressuposto necessário. Landowski (2014) descreve o regime da manipulação como aquele fundado sobre um princípio de intencionalidade no qual se

${ }^{6}$ Termo bastante utilizado por Mário Sergio Cortela (2008) 
impõem as motivações e as razões do sujeito, exigindo por sua vez um "sujeito de vontade" que avalia a situação e define suas estratégias na ação sobre o outro, agindo sobre seu querer e/ ou dever fazer algo, levando este a decidir de acordo com os interesses daquele.

Observemos o relato de P6:

\begin{abstract}
No meu primeiro contato com Lara, achei que eu a assustei um pouco, senti no jeito dela que, pelas suas reações quando conduzi já na primeira atividade física com a participação dela vi que ela estava bem desconfiada com meu "jeitão" e desconfortável com a proposta de uma atividade coletiva, interativa com ela participando integralmente. Ensinei o passo a passo pra (sic) todos individualmente e depois eles executaram a dinâmica do movimento em duplas. Fui mais descontraído que de costume já que meu objetivo naquele momento era quebrar as barreiras do espaço, do distanciamento, para promover a primeira ação de integração dela com a turma. No começo ela parece que não gostou nem de mim nem da proposta. Na segunda semana ela já veio falar comigo que foi a primeira vez. que tinha participado do comeşo ao fim das aulas de Educação Física, senti ela estava mais receptiva. De lá pra (sic) cá sempre que a encontro, brinco mudando minha voz e ela me reconhece. Já apresentei a ela as bolas de guizo que temos e que fazemos sempre jogos de interação em que jogam deficientes visuais e videntes com olhos vendados, especialmente na semana dos jogos interclasse, ela ficou bem animada, mas ainda com uma carinha de assustada. Quanto a receptividade da turma, tenho certeza que ela foi muito bem acolhida. Eles são muito carinhosos com ela, acho que até demais porque ela nem sequer sai no corredor já tem meninas junto para ajudá-la. Se ela é tão independente como a coordenação nos passou, acho que pode atrapalhar um pouco se ela se acostumar a tanta ajuda. (grifos nossos)
\end{abstract}

O que propomos com esse segundo exemplo é confirmar a base dos regimes de interação e pensar que ensinar, educar, pressupõe a existência de dois atores, dois parceiros e que vão trocar muitas coisas no campo do saber. São, portanto, dois actantessujeitos e um objeto: o saber.

Podemos observar que há uma variação das ações de interação do P5 com a Aluna Lara dentro e fora de sala de aula que é orientada, quase que exclusivamente, pelo regime da manipulação, uma vez que é fundada "sobre uma relação por natureza intersubjetiva de confiança e de persuasão, de avaliação e de troca" (Landowski, 2016, p.11). Tendo em mente seu "objetivo", P6 assume que foi "mais descontraído que de costume", o que denota o princípio da manipulação: a intencionalidade. Consciente de suas necessidades, o manipulador lança mão de diversas estratégias a fim de fazer o outro "querer" faz̧er o que ele quer, lembrando que, para que isso ocorra, é necessário "fazê-lo previamente crer ou fazê-lo saber que teria vantagem [...] em querer fazế-lo" (Landowski, 2014, p.49). Chama a atenção, também, a relação que o professor faz com o excesso de zelo da turma com Lara, apontando esse excesso de cuidado como fator que pode contribuir negativamente para sua autonomia dentro da escola, sinal de atenção ao comportamento coletivo com relação à Lara e vontade de ver o crescimento da independência da aluna.

\title{
3.3 A INCLUSÃO SOB O PRINCÍPIO DA SENSIBILIDADE
}

Outro exemplo que merece destaque é o de P2: 
Foi uma coisa engraçada, quando soube que teria uma aluna completamente cega no 9 ano não via a hora de começar, mas ao mesmo tempo tinha um certo medo, muita ansiedade. Fiquei noites sem dormir pensando em como seria, bate um medo de não conseguir explicar de modo com que ela entenda meus conteúdos. Pedi ajuda para as coordenadoras, estou lendo, pesquisando coisas na internet, experiências. Gostaria de estar preparada para este momento anteriormente. Até solicitei para a X, algum curso preparatório. A gente precisa saber como fazer. Me acalmei um pouco porque antes de entrar na sala da aluna pude conversar com a professora da educação especial da sala de recurso da escola Modelo e a mãe, soube que em Braille tem todos os símbolos químicos dá pra (sic) fazer os desenhos das ligações, etc. Minhas preocupações com Lara, nas primeiras semanas seria concernente a como ela acompanharia os cálculos, as fórmulas, as tabelas e os gráficos. Durante a semana, pude observar que ela possui grande capacidade de concentração e interesse. [...] Modifiquei minhas aulas, tornando as explicações e exemplos o mais descritiveis possivvel. Pedi que ela sempre me desse um feedback quanto a estar entendendo. Tivemos dificuldades quanto a fenômenos relacionados à luz. Mas nos saímos até bem. Estou sempre do lado dela querendo saber como ela apreende as coisas, pra (sic) que eu possa usar a forma como ela percebe para tentar explicar de modo que ela entenda._Meus conteúdos são muito visuais o que para ela ficam muito abstrato. Nos fenômenos físicos ela não vê, nos químicos não posso colocá-la para tocar ou testar. Sempre que dá estou relacionando a algo com a mesma forma para ela tocar e associar. Será um grande desafio este ano, mas desafios servem para que nós meditemos e nos aprimoremos. (grifos nossos)

Nesse relato, temos uma dinâmica que difere do anterior e se contrapõe ao primeiro aqui abordado (P5). Vemos, em uma sala de aula, o que se apresenta nas palavras de Landowski (2016):

Lá se cruzam práticas que podem corresponder, simultaneamente ou alternadamente, a qualquer um de nossos regimes. Porque nas suas interações, educator, educandum e educans não se conduzem necessariamente uns e outros segundos princípios diretores de um único e mesmo regime interacional. [...] A relação educativa toma assim, ao olhar de seus participantes, o caráter de um encontro, colocação em contato e de uma confrontação entre modos de ser e de fazer, entre estilos de existência e modos de coexistência, entre visões do mundo e modos de vida distintos ou opostos. (LANDOWSKI, 2016, p.11)

Assim, ao estabelecer correspondência das práticas pedagógicas a regimes de interação, o teórico aponta para o caráter múltiplo de possibilidades de regimes de interação em função das diversas formas de ser e objetivar fazer, assim como numa relação bastante direta com a situação e demandas.

A relação que estabelecemos de $\mathrm{P} 2$ passa pelos processos de ajustamento, no qual a relação entre sujeitos se constrói mutuamente por meio do contato. No ajuste, o regime de interação se dá não mais tendo um faz̧er crer como base, mas um faz̧er sentir em função do que os sujeitos sentem e da maneira como atuam em co-participação na construção do sentido. Assim, vemos em P2 uma presença contagiosa baseada no sentimento decorrente da vontade/ansiedade de aprender. De um lado, a professora com vontade de aprender a ensinar seus conteúdos, passar seus conhecimentos a uma aluna completamente cega; de outro, a aluna, em aprender "tanta coisa nova". Nesse percurso em que não se busca um faz̧er faz̧er, mas um faz̧er junto, numa interação em que não se pode circunscrevê-lo num papel temático, já que seus comportamentos, papéis e posições emergem pouco a pouco. A professora vai construindo sua forma de agir e transmitir 
conhecimento à aluna à medida que vai aprendendo com ela, com seu modo de apreender a realidade, numa via de mão dupla. Algo parecido com o que ocorre na dança, exemplificado por Landowski (2016). Não se trata de um ensaio de passos preparados para o palco da sala de aula, ao contrário, no envolvimento, ambos vão sentido e aprendendo o movimento com o outro.

Ao analisarmos a inclusão de uma aluna deficiente visual total em uma sala regular pela perspectiva das relações, podemos perceber mais claramente as nuances que permeiam esse importante e conflituoso processo. Ainda mais nesse tipo de deficiência, que precisa de uma maior atenção dos profissionais envolvidos devido à necessidade de interação especial no processo de ensino aprendizagem. Os materiais utilizados para trabalhar com esses educandos precisam ser adaptados e em Braille, assim como os procedimentos em aula, que devem atentar para a explicitação e descrição para melhor assimilação (BRASIL/SEESP/MEC, 2006).

Assim como a P4, que, devido ao trabalho com outra aluna com deficiência visual já na instituição há mais tempo, aprendeu a trabalhar com uma série de materiais táteis: mapas, relevos, gráficos, e que empregará também com a aluna Lara, mesmo com uma estratégia definida, as particularidades da geopolítica citada no relato instauram um novo desafio.

Mas é claro que não serão apenas os recursos e os materiais que garantirão a aprendizagem de alunos deficientes visuais. Vygotski (1997) aponta que a falta de visão não é impedimento para que esses alunos desenvolvam domínios conceituais. Afirma que não serão os exercícios táteis que possibilitarão a construção das representações mentais: mais do que isso, é importante o estabelecimento de círculos estáveis de interação social, através dos quais os conceitos serão desenvolvidos.

Assim, como apontado por Landowski (2016), não será apenas um tipo de atitude de ensino, nem uma maneira específica de ensinar, nem uma forma definida, ou conteúdo ou estatuto que encontraremos nas práticas pedagógicas, mas a superposição desses níveis e com eles, ou a partir deles, enfrentar "problemas vividos tanto pelos educadores quanto por aqueles que aspiram a 'educar' e se tentará depreender o que resulta do ponto de vista do próprio conhecimento" (LANDOWSKI, 2016, p.14).

Merece nota que o olhar sensível dos professores às reações físicas da aluna foi determinante para perceber algo que a estava incomodando e que poderia ter evoluído negativamente não fosse uma intervenção relativamente rápida. Dois relatos trouxeram informações que serviram de alerta ao setor de psicologia, reações como as descritas por $\mathrm{P} 1$ :

\footnotetext{
Algo que me deixou preocupada foi pelo fato de quando Lara não consegue resolver alguma situação escolar, ela fica incomodada e constrangida e acaba se esquivando, inclusive com queixas de dores de cabeça como se fosse uma fuga. É uma impressão particular, não sei se tem relação, mas me chamou a atenção.
}

Essa impressão de P1 foi levada à coordenação, que passou a acompanhar com os outros professores outros fatos relacionados: queixas de fortes dores de cabeça, resultando na mãe levando-a para casa antes das aulas, especificamente de Matemática. 
Em outra ocasião, passou mal novamente antes de vir à escola, com náuseas. O terceiro episódio registrado foi no dia em que a professora de Ciências havia preparado uma aula prática no laboratório. No relato da coordenação consta:

\begin{abstract}
A professora preparou uma aula no laboratório para Lara especialmente, mas ela não foi, estava doente, depois disso como não tive maiores informações, chamei a mãe para conversar, ela assumiu que a menina estava muito ansiosa, muito preocupada em "não dar conta" porque não era "muito boa em matemática". A mãe concordou que era estranho adoecer desta forma como estava ocorrendo, "ela nunca ficou assim", disse a mãe. Antes de terminar a conversa com a mãe, a aluna chegou e pude perceber pelo tom da conversa que o nível de ansiedade havia aumentado pela proximidade das primeiras provas. Ela queria continuar sendo uma aluna com notas boas e não achava que isso iria acontecer na nova escola. A acalmei quanto aos procedimentos de avaliação e encaminhei para a psicóloga. As primeiras avaliações transcorreram bem e até o presente momento não tivemos mais nenhum registro desta ordem, ao contrário, ela se mostra bem mais feliz.
\end{abstract}

A sensibilidade de P1 e a atenção da coordenação foram determinantes para a mobilização da escola na adaptação da aluna. Embora a inclusão seja uma ação que envolva a escola como um todo, o papel do professor é determinante no processo, tanto para proporcionar o envolvimento e integração com a turma, como para perceber as possíveis barreiras que se interponham à aprendizagem do aluno. Muitas pessoas cegas têm desenvolvido mais suas potencialidades na leitura, na escrita, na fala e no diálogo com os outros e apresentam grande potencial escolar e desempenho eficiente, o que parece ser o caso dessa aluna; porém, em cálculos muito abstratos, essa dificuldade parece crescer junto com a complexidade do conteúdo. Cabe à escola encontrar um caminho adequado, o que muitas vezes não ocorre, pois, se nenhuma escola está ou é preparada para o enfrentamento desses problemas, caberá somente a ela, juntamente com os envolvidos no processo, terem sensibilidade para buscarem, juntos, uma saída.

Fica claro com isso que a ação educativa requer sensibilidade do educador para com o outro, observando suas ações, o que ele diz, como diz e como ele se sente na situação: ansioso, relaxado, feliz. Landowski (2014a, p.52) chama essa sensibilidade de "sensibilidade perceptiva”, é o que, segundo ele, “[...] nos permite não apenas experimentar pelos sentidos as variações perceptíveis do mundo exterior [...], mas de sentir as modulações internas que afetam os estados do próprio corpo e de interpretar o conjunto dessas soluções [...]". Não só relacionado ao processo de inclusão, mas de modo geral, todo aluno deve ter possibilidade de expressar, para o professor e para o grupo, o que se percebe, o que sabe e o que sente.

Ainda do relato de P1, chama-nos a atenção outro trecho, agora reflexivo:

É complicado essa questão da inclusão, ninguém nunca está preparado, nem a escola nem nós, porque têm coisas que só se aprende na prática, por exemplo, se não fosse a Aluna Lara aqui, jamais iríamos nos preocupar em como fazer, qual a melhor maneira de ensinar um DV total. [...]

A adaptação da discente está ocorrendo de forma progressiva apesar do pouco tempo de convivência, acredito que estamos construindo mutuamente: colegas, professores e a instituição educacional uma relação de amizade e confiança. 
Essa reflexão nos remete a uma concepção de Nóvoa:

A formação de professores deve ser concebida como um dos componentes da mudança, em conexão estreita com outros sectores e áreas de intervenção, e não como uma espécie de condição prévia da mudança. A formação não se faz antes da mudança, se faz durante [...] (NÓVOA, 1995. p. 28).

É evidente que o processo de formação para a educação inclusiva é uma necessidade, mas, como nos apresenta Nóvoa, não pode ser desculpa para a mudança que deve ocorrer antes. Mudança no ser para mudar o fažer. Assim como a professora referida anteriormente aponta em sua fala, podemos levar em consideração que a Inclusão não é um processo rápido, nem fácil, mas requer uma preparação adequada e mudanças atitudinais de todos que atuam direta ou indiretamente. De certa forma, ela não descarta a necessidade de preparo, mas, dentro do caráter único de cada criança especial, só se saberá como fazer, fazendo; ou seja, buscando nas necessidades daquele aluno os melhores recursos para atendê-lo. Da mesma forma que justifica, aparentemente, a postura da escola em se trabalhar sob a perspectiva da demanda: "se não fosse a Aluna Lara aqui, jamais iríamos nos preocupar em como fazer, qual a melhor maneira de ensinar um DV total". O ponto mais importante é que a professora se sente desafiada a estudar e buscar informações e recursos que a ajudem na prática efetiva da inclusão e que, como viu em outros a mesma busca, ela afirma: [...] "acredito que estamos construindo mutuamente: colegas, professores e a instituição educacional uma relação de amizade e confiança”.

Não apresentaremos aqui o princípio da aleatoriedade que remete ao regime de sentido do assentimento, pelo fato de não termos encontrado, no corpus analisado, elementos que sustentassem essa abordagem.

Outro aspecto importante, porém, que ficou de fora da nossa análise em virtude da escolha metodológica que fizemos, foi o processo de inclusão sob a perspectiva da aluna Lara. No relatório que configurou nosso corpus de análise, não havia nenhum relato da própria aluna, apenas as inferências da psicóloga em seu próprio relato, quando fazia os atendimentos semanais à aluna. Em suas impressões, de modo geral, a representação da escola, dos colegas e dos professores era positiva, ou seja, a aluna dizia estar gostando muito da escola, que gostava de se sentir importante lá dentro, sendo ouvida para fazer avaliação dos indicadores táteis de acessibilidade da escola, fato que a psicóloga registrou com as palavras de Lara "Na hora que o moço disse que minha opinião era a única que realmente contava, me sentindo a tal", assim como alguns destaques feitos à gentileza das pessoas, dos colegas e ao fato dos professores explicarem "super bem". No entanto, ao mesmo tempo, a psicóloga registra um estado elevado de ansiedade e preocupação com a diferença no nível de exigência da escola atual em relação à anterior e "medo" de não corresponder com um bom desempenho nas avaliações.

Diante das anotações do último atendimento analisado, ficou visível o aumento significativo da ansiedade da aluna com o período das provas. O "medo de não dar conta", tendo em vista sua condição especial que lhe impede de determinados aprendizados, 
como em Física e Química e ancorava-se na observação que sua escola anterior era "mais fraca". Nesses registros, também constava a preocupação da psicóloga com suas faltas e dores de cabeça e mal-estar antes de algumas aulas, especialmente de matemática. Sobre esses fatos, a aluna afirmava à psicóloga ser apenas coincidência que "não tinha prestado atenção nesse detalhe". A mãe também passou a ser atendida pela psicóloga para alguns encaminhamentos, assim como os professores.

\section{CONSIDERAÇÕES FINAIS}

A escola é o espaço privilegiado como campo de interação e de construção do conhecimento. A proposta da educação inclusiva, além da simples incorporação dos alunos com NEE em salas regulares, propõe oportunizar que todas as crianças tenham as possibilidades reais de construção de seu conhecimento e desenvolvimento de suas potencialidades, independente e apesar de sua deficiência. Isso equivale dizer que, se o preparo e a formação docente forem efetivados para a educação na diversidade, aumentam as chances de uma inclusão realmente efetiva. Até porque não tem como o professor saber, "a priori", tudo sobre cada deficiência para então se sentir preparado, mesmo porque cada indivíduo apresenta características próprias dentro de uma deficiência comum. Nesse sentido, o elemento fundamental para a efetivação plena e permanente do processo inclusivo depende muito da atuação e da sensibilidade dos professores, além do apoio da escola e do acesso aos recursos necessários.

Em nossa proposição inicial, procuramos investigar os sentidos advindos das interações no contexto escolar da inclusão de uma aluna cega em uma sala de aula regular, buscando para esta análise os relatos dos professores, da aluna e do setor de psicologia sobre as ações, as impressões e preocupações dos mesmos frente ao início desse processo.

Diante das informações obtidas ao longo do estudo, foi possível identificar a preocupação dos professores em relação à inclusão da aluna Lara, a sensação de despreparo daqueles que atendem a essa realidade pela primeira vez e a boa vontade de toda a escola em dar um bom suporte para a inclusão. Em relação à receptividade e aos colegas de classe, a interação está sendo boa, mas em relação ao andamento das aulas em sala ficou claro que cada professor lança mão de um conjunto de escolhas que, por sua vez, definem a predominância em certa medida de um dos regimes de interação.

No decorrer das análises depreendidas nos relatos dos professores pelo viés dos regimes de interação, percebemos os diferentes caminhos tomados por eles na relação educativa em práticas de inclusão. Desde o papel do professor programador, como observado em P5, que busca na regularidade extrema a segurança de atingir seus objetivos (fazer saber) e para quem o aluno deficiente será sempre visto com um empecilho ao cumprimento do seu programa, já que exigiria dele ações ou apenas reações frente à necessidade de flexibilização que a inclusão requer. Por outra direção seguiu P6: fundamentou sua ação na conquista, "na relação intersubjetiva de confiança", próprias da lógica da intencionalidade, tendo como objetivo de suas ações a quebra de barreiras de espaço e distanciamento entre aluna e colegas, e aluna e professor, promovendo não apenas a integração de todos, como a satisfação da aluna Lara em participar efetivamente 
das aulas de educação física. Seu "jeitão", assumido em seu relato, nos faz relacionar sua forma de interação ao regime da manipulação.

Consideramos outra lógica ao analisar as ações de P2, a lógica construída no diálogo, na relação com o outro, na partilha de saberes e experiências próprias de cada uma para que pudessem juntas atingir o objetivo do saber. Essa professora optou por fazer o que Masini (1991, p.37) aponta como "penetrar no mundo percebido pelo DV" como ponto de contato para desenvolver seu trabalho. Não foi abordado o quarto regime de interação proposto por Landowski (2014), o acidente, por não constituir evidências em nenhum dos relatos analisados.

Por fim, ressaltamos que nossa análise tratou de um pequeno recorte da complexidade que são as relações diárias no cotidiano de uma sala de aula. Recortamos apenas num aspecto da inclusão de uma aluna deficiente visual total inserida no nono ano de uma turma regular em seu momento inicial. Dessa realidade observada, do que é discutido e apontado na educação inclusiva e da teoria que ampara nossa análise, acreditamos que, numa relação de inclusão de alunos com deficiência visual, para que se possa chegar mais rápido a uma inclusão real, a formação de professores deveria iniciar pela lógica relacional da sensibilidade, cujas interações são regidas pela proximidade, pelo contato, pelo contágio; inclusive no princípio da alteridade. Nessa relação, percebe-se uma busca maior que um fazer-fazer ou um fazer-saber, porém um fazer e um saber junto, em ato, como um aprendizado entre os interactantes, próprio do regime de ajustamento. Posição que nos faz retomar o fragmento em epígrafe deste trabalho como ponto de ancoragem da educação inclusiva: "A escola não pode tudo, mas pode mais. Pode acolher as diferenças".

\section{REFERÊNCIAS BIBLIOGRÁFICAS}

ABRAMOWICZ, Jaqueline (org.) Para além do fracasso escolar. Campinas, SP: Papirus, 1997.

AMIRALIAN, Maria Lucia Toledo Moraes. Comunicação e participação ativa: a inclusão de pessoas com deficiência visual. In: AMIRALIAN, Maria Lucia Toledo Moraes. (Org.) Deficiência visual: perspectivas na contemporaneidade. 1. ed. São Paulo: Vetor, 2009.

BRASIL/SEESP/MEC. Orientações para implementação da politica de educação especial na perspectiva da inclusiva. Disponível em: http://www.pmpf.rs.gov.br/servicos/geral/files/portal/Documento_Subsidiario_Educ acao_Especial.pdf. Acesso em 04 fev. de 2015.

. Declaração de Salamanca e linha de ação sobre necessidades educativas especiais. Brasília, DF: CORDE, $1994 . \quad$ Disponível em: <http://portal.mec.gov.br/seesp/arquivos/pdf/salamanca.pdf> Acesso em 04 fev. 2016. 
- Experiências educacionais inclusivas: Programa Educação Inclusiva: direito à diversidade / Organizadora, Berenice Weissheimer Roth. - Brasília: Ministério da Educação, Secretaria de Educação Especial, 2006.

. Lei de Diretrizes e Bases da Educação Nacional - LDB (Lei no 9394/96). 20 de dezembro de 1996.

FABRI, Paolo. Campo de manobras didáticas. . Revista Entreletras, v. 7, n. 2, 2016. p. 1924, jul-dez 2016.

FERREIRA, P. \& GONÇALVES, A. G. Perspectiva Histórica do Processo de Inclusão de Pessoas com Necessidades Educacionais Especiais na Política Educacional Brasileira. Revista Científica Eletrônica de Pedagogia. São Paulo, ano 5, n. 9, Jan. 2007. Disponível em:

http://www.revista.inf.br/pedagogia09/pages/artigos/edic09-anov-art06.pdf Acesso em: 02 fev. 2016.

GREIMAS, A.J. e COURTÉS,J. Dicionário de semiótica. São Paulo: Contexto, 2008.

LANDOWSKI, Eric. Presenças do outro. São Paulo: Perspectiva, 2005.

2014.a.

Interações arriscadas. Trad. Luiza Silva. São Paulo: Companhia das Letras e Cores,

. Sociossemiótica: uma teoria geral do sentido. Galaxia (São Paulo, Online), n. 27, p.

10-20, jun. 2014.b. Disponível em http://dx.doi.org/10.1590/1982-25542014119609. Acesso em 12 de março 2016.

. Regimes de sentido e formas de educação. Revista Entreletras, v. 7, n. 2, 2016. p. 814, jul-dez 2016.

MASINI, Elcie F. Salzano. O perceber e o relacionar-se do deficiente visual, orientando professores especializados. Em: CARVALHO, S.; DIAS, T.R. da S.; FERREIRA, J.R. (eds) Revista Brasileira de Educação Especial Vol. 1, $\mathrm{n}^{\circ}$ 1, 1992. Disponível em: http://www.abpee.net/homepageabpee04_06/artigos_em_pdf/revista1pdf/r1art03.pdf Acesso_em 02 de fev. 2016.

NÓVOA, Antonio. Os professores e sua formação. Lisboa: Don Quixote, 1995.

ZILBERBERG, Claude. Elementos de semiótica tensiva. Tradução de I. C. Lopes, L. Tatit e W. Beividas. São Paulo: Ateliê Editorial, 2011. 